\title{
ADDENDUM
}

\section{Mechanochemistry: Forcing a molecule's hand}

S. Karthikeyan and Rint P. Sijbesma

Nature Chemistry 2, 436-437 (2010); published online 21 May 2010, corrected after print 25 March 2015.

The Journal of the American Chemical Society article on which this News \& Views is based was retracted (K. M. Wiggins et al. Retraction of mechanical reconfiguration of stereoisomers. J. Am. Chem. Soc. 137, 3428; 2015) on 11 March 2015 after an investigation at The University of Texas at Austin found that the data and conclusions reported in the study are unreliable. 